\title{
OS SAN, OS KHOEKHOEN: EXERCÍCIOS DE APROXIMAÇÃO
}

\begin{abstract}
Ana Lígia Leite e Aguiar ${ }^{1}$
Resumo: Este trabalho procura fazer uma breve apresentação dos povos originários da África do Sul, os San e os Khoekhoen. Focando na análise de verbetes e de expressões cunhadas por uma historiografia clássica, pretende-se analisar de forma crítica os modos como tais povos foram descritos ao longo dos anos. O termo genérico "Khoisan", que abarca vários grupos indígenas do sul da África, servirá como ponto de mediação para se compreender o entrelaçamento de grupos distintos ao longo dos séculos.
\end{abstract}

Palavras-Chave: San. Khoekhoen. África do Sul. Historiografia crítica.

\section{THE SAN, THE KHOEKHOEN: APPROACH EXERCISES}

\begin{abstract}
This work is a brief attempt to hold a dialogue on South Africa's people: the San and the Khoekhoen. Concentrating on the study of the lexicon and articulation conceived by classical historiography, here we contemplated an analytical thinking about how the history of these people were narrated throughout the years. The collective term "Khoisan", which encloses several indigenous groups in southern Africa, will provide a starting point in order to understand the correlation of distinct groups over the centuries.
\end{abstract}

Keywords: San. Khoekhoen. South Africa. Critical historiography.

Narrar um povo nos impõe a tarefa de uma dupla percepção: é preciso estar ciente das multiplicidades que escapam ao ato da escritanarração e é preciso estar ciente que os equívocos de identidade prontamente se revelarão, pois ao compararmos, e essa seria a regra constitutiva da antropologia (VIVEIROS DE CASTRO, 2006), incorremos no perigo que toda comparação abarca:

\footnotetext{
*Esta pesquisa foi parcialmente financiada pela Coordenação de Aperfeiçoamento de Pessoal de Nível Superior - Brasil (Capes) - Finance Code 001.

${ }^{1}$ Ana Lígia Leite e Aguiar. Mestre e Doutora em Documentos da Memória Cultural pela Universidade Federal da Bahia (2004 e 2010). Professora de Literatura Brasileira do curso de Letras da Universidade da Bahia. Pesquisa Literatura Brasileira, Crítica Biográfica, Literatura Comparada, Estudos sobre a Nação e Estudos da Imagem. Pesquisadora associada desde 2020 ao CAS (Centre for African Studies/ Pre-colonial \& Heritage Studies), na Cidade do Cabo, na África do Sul.
} 
É aqui que as coisas se complicam bastante, como mostrou Talal Asad em um notável artigo. Eu adoto a posição radical que é, penso, a mesma de Asad, e que resumo dizendo que, em antropologia, a comparação serve à tradução e não o contrário. A antropologia compara para traduzir, e não para explicar, justificar, generalizar, interpretar, contextualizar, revelar o inconsciente [...]. E direi também que se traduzir é sempre trair [...] a boa tradução [...] é aquela que trai a língua de destino, não a língua do original (VIVEIROS DE CASTRO, 2006, p. 147).

Estejamos cientes, diante do exposto, que os exercícios aqui propostos serão mais exercícios de equivocação do que de qualquer tentativa de alcançar a certeza narrativa. Portanto, o retrato que os San e os Khoekhoen ganharão neste artigo, está longe, bem longe daquilo que teriam sido ou daquilo que virão a ser. Caçadores-coletores, os San são os povos mais antigos do sul da África, e hoje se encontram na Namíbia, em Botswana, na África do Sul, em Angola, no Zâmbia, em Lesoto e no Zimbabwe. Geneticistas apontam que as mais antigas amostras de genes modernos encontradas vieram dos San e datam de cerca de 80.000 anos atrás. Conhecidos como povos nômades ou seminômades, o termo San (Saan, Sãn), no idioma Khoekhoegowab, “provavelmente se refere a pessoas sem gado ou pessoas que forrageiam por sua própria comida. É geralmente aplicado aos povos caçadores e coletores do sul da África, que descendem dos primeiros homens modernos desta região [... ]"2. Em outra tentativa de definição, a palavra San surge de forma mais assertiva, significando "povos que colhem comida selvagem". ${ }^{3}$ No National Geographic, tem-se:

Hoje, muito poucos San estão aptos a viver de caça e de coleta de alimentos. A maioria trabalha para fazendas, ou vivem desempregados em assentamentos, trabalham em seus projetos próprios de geração de renda, administram unidades de conservação da natureza, alguns ainda caçam e coletam, e outros não têm outra fonte de renda

${ }^{2}$ Disponível em: http://www.san.org.za/history.php. Acesso em: 30 ago. 2020.

${ }_{3}^{3}$ Disponível em: http://www.san.org.za/terms.php. Acesso em: 30 ago. 2020. 
que não seja uma pequena pensão do Estado ${ }^{4}$ (National Geographic, 2017).

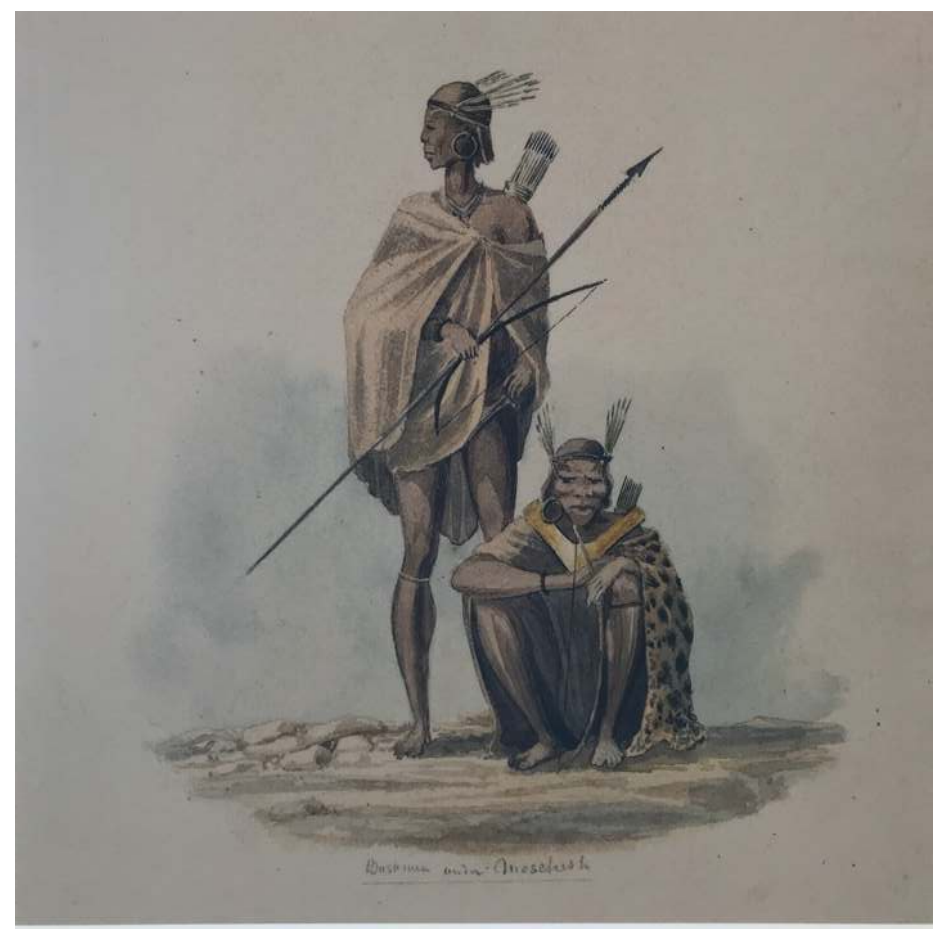

San under Moshoeshoe, by Charles Davidson Bell, 1834

Galeria do !Khwa ttu Museum. Imagem da autora (2020).

As variadas funções descritas acima desempenhadas pelos San estão atreladas a uma busca contínua em se fazerem vistos ou em serem reconhecidos como os primeiros habitantes do sul da África. John Laband assim escrevera em sua obra The land wars.

De todos os povos que vivem na África do Sul hoje, apenas os San são considerados autóctones - isto é, ainda vivem na mesma região que seus ancestrais quando evoluíram para os humanos modernos há muito tempo. Todos os outros envolvidos nesta história eram colonos, pessoas que vieram depois, quer migrando mais para o norte da África como os Khoikhoin e os falantes de Nguni do Sul,

\footnotetext{
${ }_{4}$ Disponível em: https://blog.education.nationalgeographic.org/2017/03/29/san-people-draft-code-ofethics-for-researchers/. Acesso em: 30 ago. 2020.
} 
ou chegando via mar da Europa como portugueses, holandeses, franceses, britânicos e alemães, ou de Madagascar, das Índias Orientais e de outras partes da África se fossem escravizados (LABAND, 2020, p. 3).

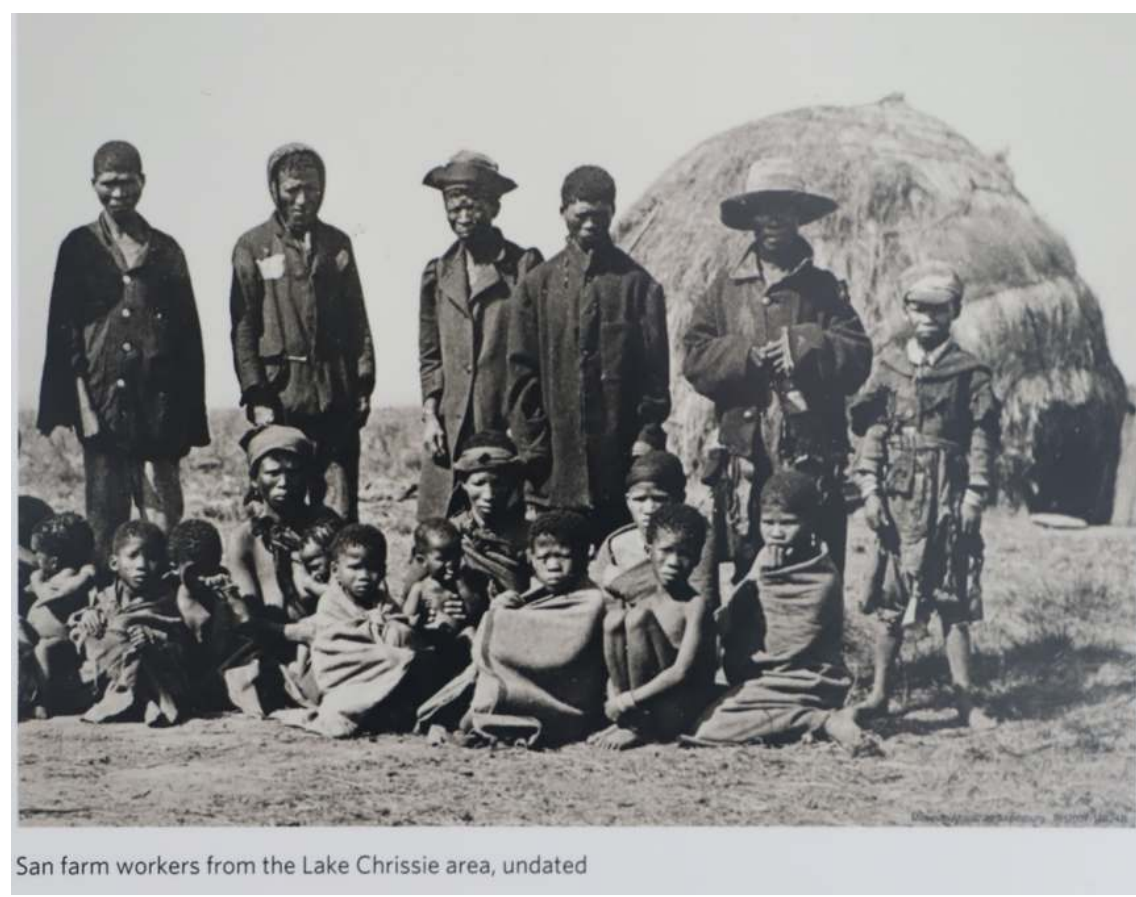

Galeria do !Khwa ttu Museum. Imagem da autora (2020).

No mais das vezes, ainda é possível encontrar quem se refira aos autóctones como bushman, bosquímanos ou hotentotes. "Por sua língua típica, foram chamados de 'hotentotes' (ou 'gagos', em neerlandês), e pelas práticas de caça e coleta foram denominados 'bosquímanes' (derivação do inglês ‘bushman' ou homem do mato)". ${ }^{5}$ Esses termos, utilizados há mais de três séculos para se referir aos San, aos Khoekhoen, aos Nama, aos Griqua, dentre alguns outros, são verbetes cunhados por estrangeiros que descreviam os povos locais a partir de suas observações. Evitando e renegando os termos impostos pela chegada dos colonizadores e de suas conceituações, as nomeações, no presente, podem ser feitas pelos nomes mesmo das etnias, tal

${ }^{5}$ Disponível em: https://aventurasnahistoria.uol.com.br/noticias/reportagem/o-caso-da-venus-hotentotequando-o-imperialismo-europeu-foi-longe-demais.phtml. Acesso em: 15 out. 2020. 
como a tradição desses povos, ao que tudo indica, lhes transmitiu, ou tal como o tempo presente nos aconselha a fazer. Acerca disso, é possível também localizar algumas reivindicações para o termo bushman, por exemplo, ${ }^{6}$ reascendendo a discussão acerca das reapropriações que termos cunhados pela razão hegemônica eurocêntrica têm ganhado no contemporâneo.

No !Khwa ttu Museum, em Yzerfontein, é possível ler em uma das paredes uma descrição resumida dos Khoekhoen: "Quando os holandeses se instalaram na Baía da Mesa em 1652, havia muitos grupos Khoekhoen, incluindo os Griqua, os Chainouqua, os Cochoqua, os Hesequas, os Attaqua, os Guriqua, os !Ora e os Namaqua na área." de Wilfrid Haacke e Eliphas Eiseb, as definições etimológicas Khoe aparecem como "homem", "pessoa", mas também se relacionam com os falantes da língua Khoekhoegowab (2002, p. 72):

authentic name]; obs. Nama/Damara (language); Khö̀khò̃gòwà-ùa \{Khoekhoegowa-a\} v.t speak Khoekhoe to (s.o.); khờn (di) đ̀àlgôab \{khoen ôalgôab\} $n$. Bibl. mortal man, son of man; khø̋en (di) lhàds \{khoen lhaos\} $n$. gathering of people; Khòèn Öab \{Khoen Ôab\} $n$. Son of Man (i.e. Christ); khòed \{khoeo\} a. devoid of people, uninhabited; khôe-òmgùra, in-òngùra \{khoe-omgura, lî-omgura\} n. married couple; khøe-б6rèb/s \{khoe-oreb/s\} $n$. (human) cannibal [esp. in folklore]; fig. cannibalistic anim.; khðèds̀b \{khoeosib\} $n$. uninhabited state/condition; khøè- âgùn \{khoe-ôagun\} $n$. members of a core/nuclear family; khồè- $\delta$ ăgù(\$i)b \{khoe-ôagu(si)b\} n. nuclear/core family khồb \{khoeb\} n. man; husband [Hm]; s.a. ÁÒB, ÀRO-/KÄLKHOÖÈB; (ra) kai bec. a hum.b. (e.g. of: Deity/fabulous being), bec. incarnate; khòe-i \{khoe-i\} $n$. human being, person; someone; khöen \{khoen\} $n$. (the) people; khòs \{khoes\} $n$. woman; lady; khð̀gürıgùkha/ra \{khoegurigukha/ra $\boldsymbol{n}$. (two) colleagues; khð̋ehőrésägùb/s $\{$ khoehoresagub/s\} n. s. XĀSỈB; khø̈kăisııb \{khoekaisib\} $n$. incarnation; Khðekhò̀n \{Khoekhoen\} n. (pl. only) people speaking the $\sim$ language [today esp. Nama, Damara, Hailom; formerly also Cape Khoe]; khôekhdës* \{khoekhoes\} n. Lit. personification; khöekhdègòwà \{khoekhoegowa\} v.i speak the Khoekhoe language (Nama/ Damara); Khðèkhðёgòwàb \{Khoekhoegowab) $n$. Khoekhoe language [revived

Imagem de A Khoekhoegowab Dictionary(2002).

Assim, os pastores-nômades/ semi-nômades Khoekhoe, Khoi, Khoe, Khoikhoi, Khoikhoin, Cóis ou Khoekhoen acabaram sendo fundidos aos

\footnotetext{
${ }^{6}$ Confira em: https://www.youtube.com/watch?v=HOdw3mv7JSo\&t=478s. Dos 18"' aos 56"'. Acesso em: 30 ago. 2020

7 Visita ao !Khwa ttu Museum, em Yzerfontein, em 13 de agosto de 2020.
} 
caçadores-coletores San e os dois grupos foram sendo descritos por um termo genérico que acabou por uni-los, fazendo-os ser conhecidos por Khoisan/ Coissãs/ Coisãs/ Khoesan. De tal modo que o termo "Khoisan" foi o que se alastrou por toda a parte sul-africana, incluindo os outrora "hotentotes" (cóis) e "bosquímanos" (sãs) do sudoeste de África. ${ }^{8}$ Ainda no !Khwa ttu Museum, podemos ver que o termo "Khoisan", introduzido por acadêmicos no início do século XX, é tema de cuidados quanto ao seu uso.

A história dos San junto à história dos Khoekhoen, e à de muitos outros povos, está entrelaçada, ainda que tenham existido inúmeras diferenças entre eles. A própria cisão do termo "Khoisan", no presente, tem apontado para as especificidades que se pretende demarcar entre povos, desfazendo a aparente naturalidade que por muitos anos permitiu que o nome dos San viesse anexado ao nome dos Khoekhoen. Jared Diamond, em seu livro Armas, germes e aço, assim se referiu aos Khoisan:

\begin{abstract}
Alguns dos povos coissãs nativos da África do Sul (também conhecidos como hotentotes ou bosquímanos) adquiriram o gado, mas permaneceram sem agricultura. Eles foram ultrapassados em quantidade e substituídos a nordeste do rio do Peixe pelos lavradores africanos, cuja expansão para o sul foi sustada ali. Somente quando os colonos europeus chegaram por mar em 1652, trazendo com eles o pacote de produtos agrícolas do Crescente Fértil, a agricultura pôde se desenvolver na zona mediterrânea da África do Sul. Os choques de todos esses povos produziram as tragédias da África do Sul moderna: a rápida dizimação dos coissãs pelos germes e pelas armas dos europeus; um século de guerras entre europeus e negros; outro século de opressão racial; e agora, tentativas de europeus e negros para buscar um modo novo de coexistência nas antigas terras coissãs (DIAMOND, 2013, p. 130).
\end{abstract}

Essa complexa relação, aceita como a união entre diferentes grupos que viriam a se conformar no significante "índios", passou a se configurar assim, como mostra a literatura, tanto pelo fator genérico que toda colonização implica, quanto pelo fato de, no passado, os Khoekhoen e os San

8 Disponível em: https://ec.europa.eu/translation/portuguese/magazine/documents/folha40_pt.pdf. 
terem estado em diferentes lados, antes e depois da chegada dos primeiros colonos, para depois se unirem no combate ao estrangeiro sem precedentes que se impunha sobre seus territórios. Essa história conhecemos bem: se no Brasil os povos originários se aliaram a portugueses, a holandeses ou a franceses, buscando vantagem sobre inimigos ancestrais, o mesmo ocorre com os povos originários do sul do continente africano. Devagar, cairão no arrependimento por terem se aliado aos novos inimigos e, devagar, buscarão refazer alianças com antigos oponentes. Mohamed Adhikari, em seu artigo "A total extinction confidently hoped for: the destruction of Cape San society under Dutch colonial rule, 1700-1795", relata que:

Como clientes e servos de trekboers [os bôeres eram europeus, em sua maioria descendentes de holandeses, havendo em menor parte alemães e franceses], os Khoikhoi eram frequentemente cúmplices da violência contra San e muitos participavam de ataques de comandos como substitutos de trekboers relutantes. Uma razão para essa animosidade era que muitas vezes eram os servos Khoikhoi que suportavam o peso dos ataques de San e muitos eram mortos enquanto cuidavam dos rebanhos dos fazendeiros. [...] Os dependentes de Khoikhoi que tiveram permissão para manter estoque foram igualmente ameaçados por ataques San. Alguns comandos, especialmente na última parte do século XVIII, tinham a maioria de membros Khoikhoi. Havia algum incentivo para Khoikhoi entrar no comando, pois muitas vezes recebiam uma parte dos despojos, embora menores que os dos trekboers. Eles podiam obter alguns dos animais recuperados ou mulheres San capturadas como parceiras sexuais. Khoikhoi eram batedores e rastreadores habilidosos e rotineiramente enviados para situações perigosas onde os trekboers não estavam preparados para arriscar suas próprias peles. Muitos participantes Khoikhoi, nas palavras de Nigel Penn, provavelmente calcularam que, 'Era melhor ser um membro de baixo status de um comando do que um objeto indefeso de sua ira.' A relação entre San e Khoikhoi era, no entanto, complexa. As comunidades pastoris Khoikhoi independentes além da fronteira colonial estavam frequentemente em conflito com os San, que atacavam seu estoque. Caçadorescoletores às vezes também eram considerados clientes na 
sociedade Khoikhoi e não era incomum para um Khoikhoi despossuído se juntar aos San na resistência à intrusão colonial (ADHIKARI, 2010, p. 32).

Podendo ser esta uma das genealogias para que o termo "Khoisan" tenha ganhado tamanho fôlego, as especificidades destes grupos se fariam sentir frente a outras etnias. Gilberto Freyre teria escrito em Casa Grande e Senzala, quando descreve a variedade de populações traficadas para o Brasil no período da escravidão, sobre a "cor de couro dos hotentotes e dos boximanes" (2002, p. 201). E compara valorando, como atesta a metodologia empregada em sua obra (gerando sempre espanto na contemporaneidade):

O sudanês é um dos povos mais altos do mundo. No Senegal veem-se negros tão altos que parecem estar andando de pernas de pau; tão compridos dentro de seus camisões de menino dormir que de longe parecem almas do outro mundo. Magricelas, dentuços, angulosos, hieráticos. Mais para o sul da África, é que se encontra gente baixa e redonda. Mulheres culatronas. Redondezas afrodisíacas de corpo. Hotentotes e boximanes verdadeiramente grotescos com as suas nádegas salientes (esteatopigia) (FREYRE, 2002, p. 206).

As nádegas - como uma das formas às quais os corpos dos "Khoesan" foram reduzidos - terão chamado bastante atenção: "Os coissãs [...] antigamente distribuídos por grande parte da África meridional, [...] são (ou eram) bem diferentes, na apare`ncia, dos negros africanos: suas peles são amareladas, o cabelo é bem encarapinhado e as mulheres tendem a acumular muita gordura nas nádegas (DIAMOND, 2013, p. 277). Michael Wessels assim escrevera:

Os discursos sobre espiritualidade e sexualidade Khoisan mostram o impacto de eventos mais amplos. Yvette Abrahams (1997) encontra flutuações comparáveis na representação da sexualidade Khoisan àquelas que Chidester (1996) discerne em relação à religião. Ela observa que as fases anteriores do colonialismo correspondiam a um fascínio pelo suposto pênis Khoisan semiereto e ausência de um testículo enquanto a atenção se voltava para a anatomia feminina, notadamente o 
'avental Hottentot' (lábios alongados) e nádegas (esteatopigia), durante o período em que a resistência anticolonial estava no auge (WESSELS, 2012, p. 190).

Se no Brasil pouco sabemos sobre os povos Khoekhoen e os San, é preciso que contrastemos essa informação com a de que pelo menos algumas centenas de pessoas conheçam a trajetória de uma mulher Gonaqua (descendentes dos Khoekhoen e dos Xhosa) reivindicada como "Khoesan".

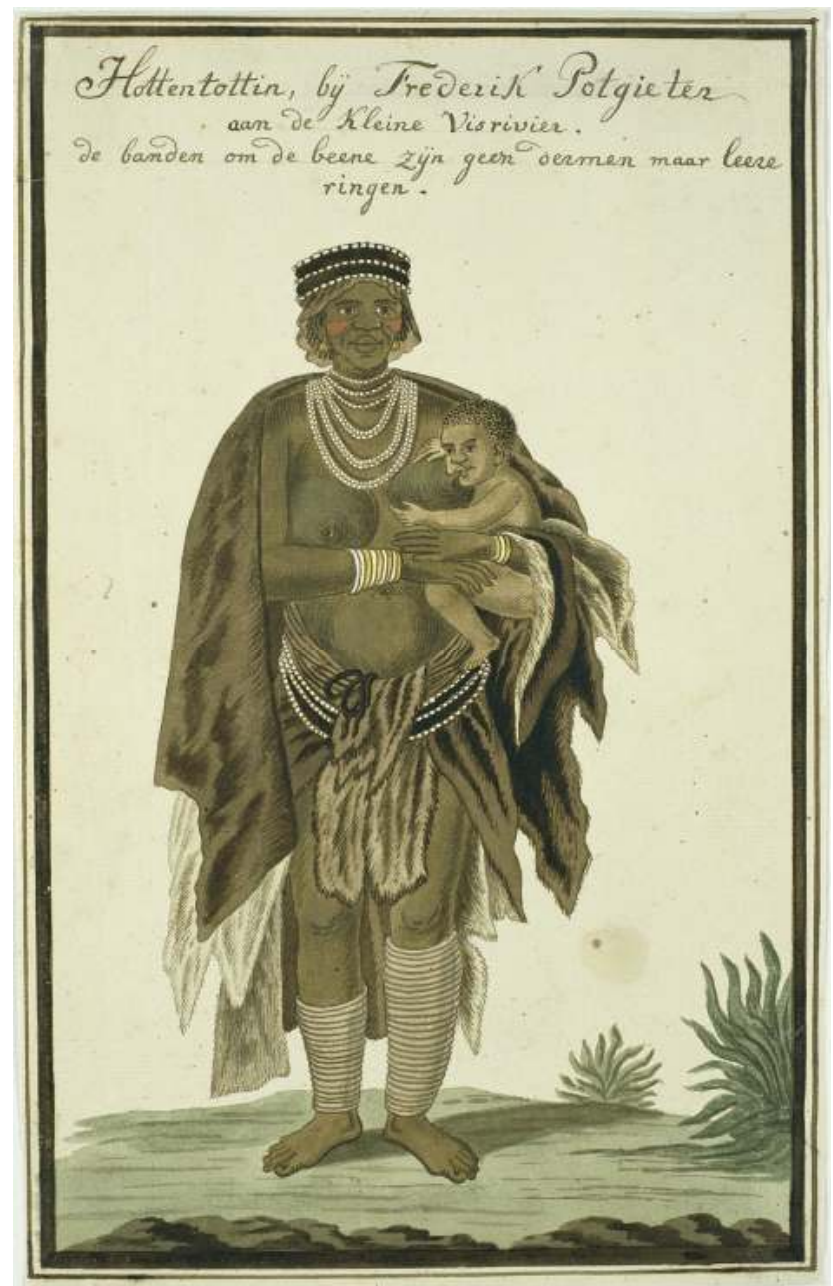

Khoikhoi or Gonaqua woman with a child at the breast, Robert Jacob Gordon (attributed to), 1777-1786. Disponível em:

https://www.rijksmuseum.nl/en/search/objects?set=RP-T-1914-17A\#/RP-T-1914-17-81, 13 


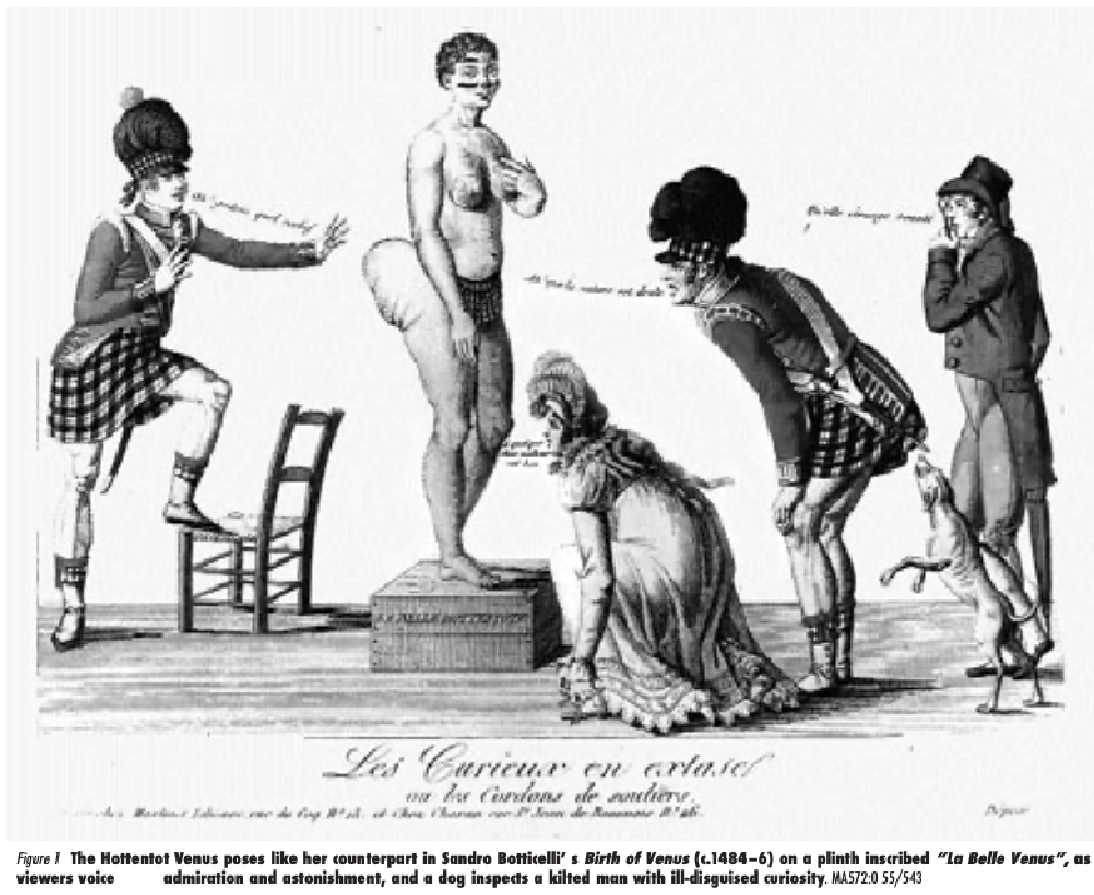

Sara Baartman. Imagem do livro Miscast (1996), p. 349.

Não se conhece seu nome original, mas Sara Baartman é seu nome em Afrikaans. Tendo sido uma grande vítima do racismo científico, ficou conhecida como Vênus Hotentote ou Vênus Negra, nomes depreciativos por razões previamente rascunhadas aqui, ao que Freyre chamou de "redondezas afrodisíacas de corpo" (FREYRE, 2002, p. 206). Foi exposta em um circo, após ter sido levada para a Inglaterra, ${ }^{9}$ devido à enorme curiosidade que alguns aspectos de sua fisionomia e a gordura nas nádegas despertaram nas mentalidades fixadas na hierarquia de "raças". Se os registros sobre seu nascimento estiverem certos, ela vivera por volta de 25 anos. O percurso biográfico de Baartman analisado por Simone Kerseboom em seu artigo

\footnotetext{
9 Um percurso biográfico mais detalhado sobre Sara Baartman pode ser encontrado no artigo "Encenando a diferença em palcos metropolitanos: as trajetórias de Sara Baartman e Franz Taibosh", de Juliana Braz Dias e Geovanna Belizze. Disponível em: https://journals.openedition.org/aa/6697. Acesso em: 25 nov. 2020.
} 
"Grandmother-martyr-heroine: Placing Sara Baartman in South African postapartheid foundational mythology" critica o modo como o corpo de Baartman ${ }^{10}$ sofre uma segunda reapropriação: servirá à construção mitológica na África do Sul que tenta se recuperar do trauma de 46 anos de Apartheid (1948-1994).

No entanto, a história de Baartman, firmemente colocada na história colonial, se tornaria uma narrativa simbólica poderosa para a transição na África do Sul. Moudileno afirma que foi justamente o fim do apartheid na África do Sul que permitiu a possibilidade do retorno de Baartman porque "essa virada geopolítica permitiu que o caso de Baartman fosse reaberto, já que até então seu valor simbólico pertencia a um trágico mas um passado colonial remoto cuja ligação com o presente era inexistente". Para Moudileno, o corpo de Baartman passa por uma metamorfose de um local de temporalidade colonial para um remanescente assustador que está incluído no panteão pós-apartheid de ícones quase exclusivamente masculinos. No entanto, o pedido da Conferência Nacional Griqua a Nelson Mandela para assumir a causa do retorno dos restos mortais de Baartman à África do Sul em 1995 significava que Baartman se tornaria parte de uma agenda nacional, em vez de um ícone Khoisan exclusivo. Verdery argumenta que as figuras fundadoras mortas, caladas, são ambíguas e isso permite sua eficácia simbólica. O que é compartilhado pela nação é o reconhecimento desses indivíduos como sendo importantes e que a ambiguidade - que pode evocar uma variedade de entendimentos - é justamente o que dá aos indivíduos falecidos - simbólica ou concretamente - sua eficácia como instrumento político (KERSEBOOM, 2011, p. 67).

O caso de Sara Baartman é um caso paradigmático das violências da representação. Muitos casos em suas especificidades mais discrepantes ocorreram, como se pode recuperar na obra Miscast: Negotiating the Presence of the Bushmen, editado por Pippa Skotnes.

${ }^{10}$ Confira mais sobre a história de Sara Baartman na obra Miscast: Negotiating the Presence of the Bushmen, editado por Pippa Skotnes. 
A maioria dos museus sul-africanos inclui seções sobre os bosquímanos. Geralmente, eles se dedicam a revelá-los como caçadores-coletores atemporais e a-históricos, vistos quase nus e colocados em dioramas, que mostram uma paisagem imaculada na qual nenhuma intrusão estrangeira é evidente. Essa imagem é explorada ainda mais por anunciantes e cineastas populares, que perpetuam a imagem dos bosquímanos como expulsos do tempo, da política e da história - miscast (SKOTNES, 1996, p. 17).

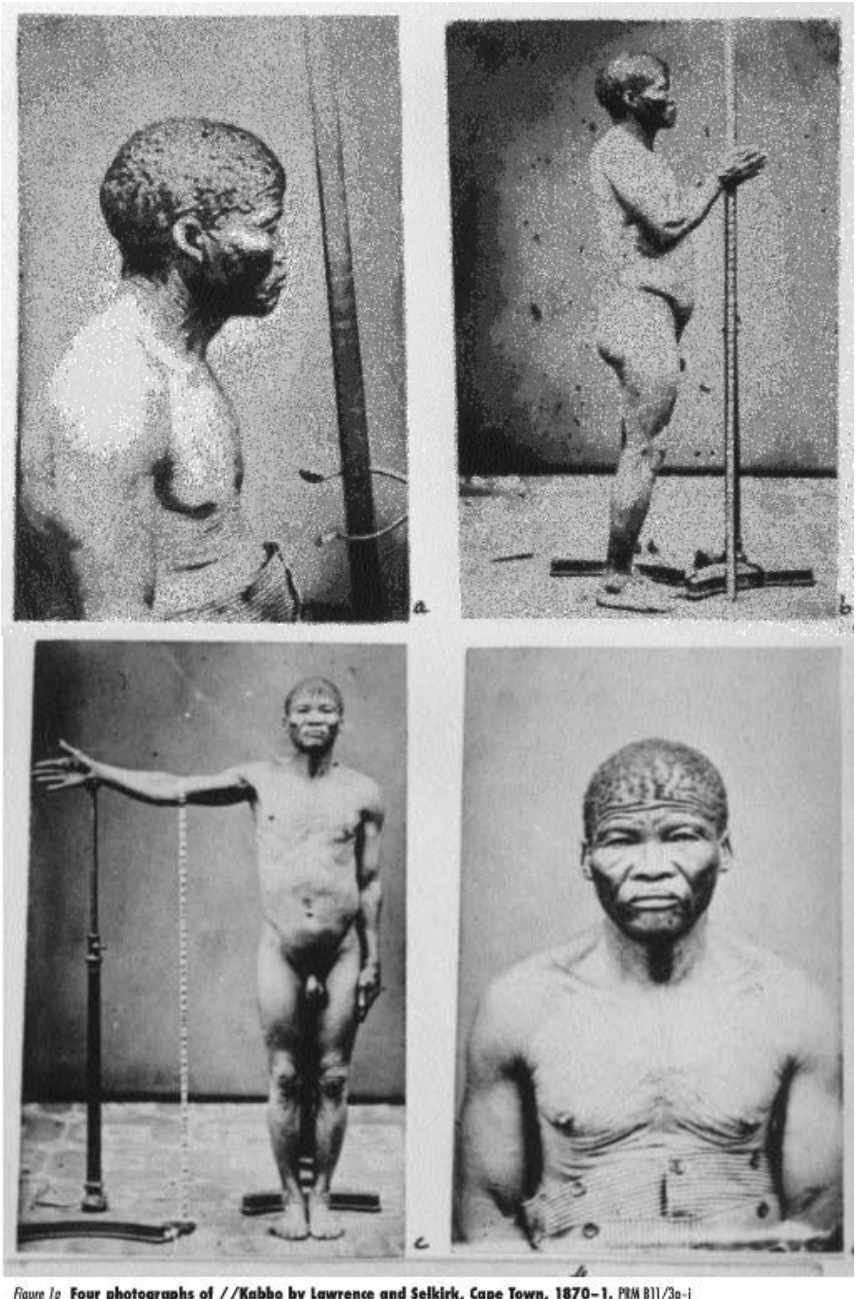

Imagens do livro Miscast(1996), p. 117. 
Entre 1870 e 1940 os San e os Khoekhoen, e vários outros grupos, foram objetos de inúmeras práticas de códigos violentos aos quais os povos originários do sul da África foram submetidos. O gesto do casting, de fazer moldes de pessoas, para faces, para partes específicas do corpo, fundindo-as em uma forma, tal como o gesto da fotografia antropológica que hierarquiza, mede, cataloga aquilo que o olho não suporta como diferença e interpreta como anomalia, poderia apontar para o fim precoce e trágico do próprio berço da humanidade. Entranha ambiguidade para a qual nos conduz o gesto contido nessas imagens, nos levando a pensar que nós, homens modernos, não conseguimos resistir ao impulso de tentar matar os nossos próprios genitores.

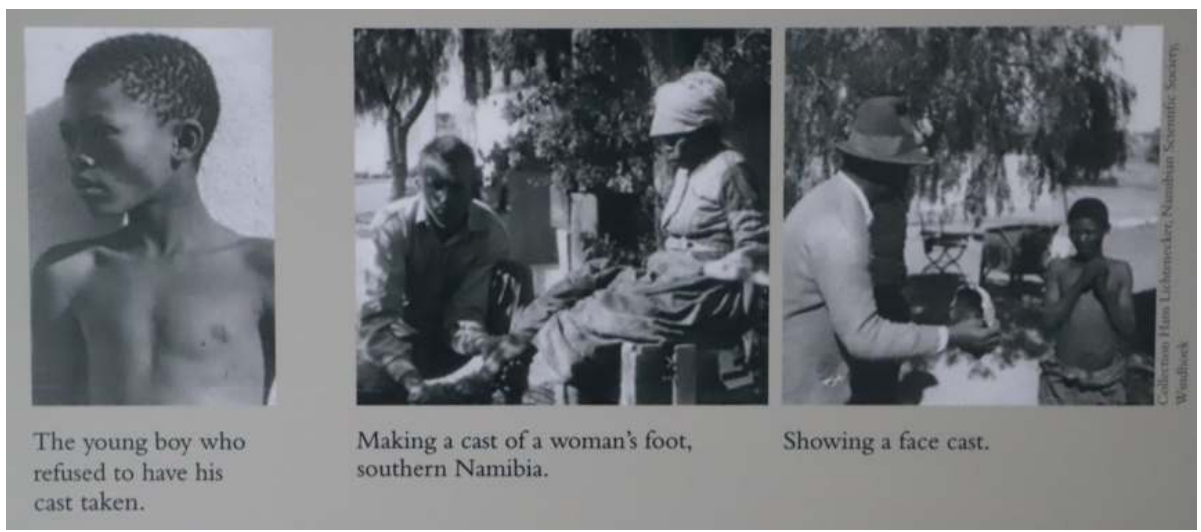

Galeria do !Khwa ttu Museum. Imagem da autora (2020).

\section{À guisa de uma conclusão}

Para não finalizar engrossando o coro trágico, a história dos descendentes dos Khoekhoen/ San/ "Khoesan" supostamente apontaria para um fim precoce, mas a investida no presente tem sido a de se encontrar ferramentas que viabilizem um outro entendimento sobre essas etnias. A Universidade da Cidade do Cabo, em 2019, incluiu o idioma Khoekhoegowab na oferta de cursos livres da Universidade. ${ }^{11}$ O retorno ao estudo e à pesquisa de mais uma língua ancestral está aliado aos longos caminhos de combate à

\footnotetext{
11 Um pouco mais sobre o curso pode ser conferido em uma entrevista com June Bam-Hutchison em: https://www.iol.co.za/capeargus/news/pics-khoisan-tribes-meet-on-table-mountain-in-bid-to-reclaimthe-mountain-in-the-sea-5ac3db0b-22a9-4d20-a647-73954b1220b5. Acesso em: 27 out. 2020.
} 
degradação ambiental e à mineração, aos safaris de luxo, e investe na preservação de museus a céus abertos, onde residiam esses povos milenarmente, em meio a cavernas ora à beira do mar, ora encrustadas na floresta. A medicina e a plantação tradicionais seguem o percurso desobediente e necessário. Recentemente um grupo "Khoisan" se instalou em uma parte da floresta da montanha, a Baía da mesa. Nem tudo é esquecimento e preconceito. E o que seriam as discussões sobre o antropoceno, senão a alucinada tentativa em nos dizer que é preciso recuarmos todos e que é preciso, de uma forma ou de outra, voltarmos a ser um pouco "índios"?

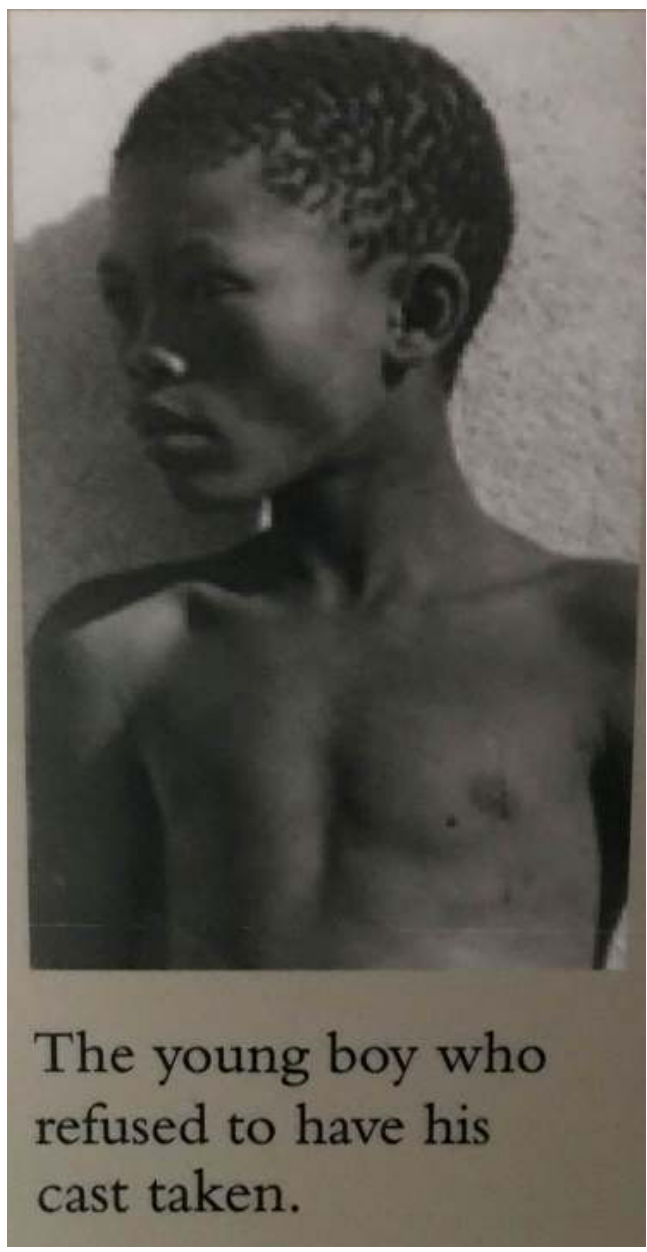

Galeria do !Khwa ttu Museum. Imagem da autora (2020). 


\section{Referências}

ADHIKARI, Moamed. A total extinction confidently hoped for: the destruction of Cape San society under Dutch colonial rule, 1700-1795. Journal of Genocide Research, 12:1-2, 19-44, 2010, DOI: 10.1080/14623528.2010.508274.

DIAMOND, Jared. Armas, germes e ac, o: os destinos das sociedades. Rio de Janeiro: Record, 2013.

FREYRE, Gilberto. O escravo negro na vida sexual e de família do brasileiro. In: SANTIAGO, Silviano (Coord.). Intérpretes do Brasil, Vol. 2, Rio de Janeiro, Nova Aguilar, p. 396-476, 2002.

HAACKE, Wilfrid; EISEB, Eliphas. A Khoekhoegowab Dictionary with an English-Khoekhoegowab. Windhoek/ Namíbia: Gamsberg Macmillan, 2002.

KERSEBOOM, Simone. Grandmother-martyr-heroine: Placing Sara Baartman in South African post-apartheid foundational mythology, Historia 56, 1, Mei/May, p. 63-76, 2011.

LABAND, John. The land wars: The Dispossession of the Khoisan and AmaXhosa in the Cape Colony. London, Penguin Random House South Africa, 2020.

MARKS, Richard Lee. Three men of the Beagle. New York: Knopf, 1991.

MOUDILENO, Lydie, Returning Remains: Saartjie Baartman, or the 'Hottentot Venus' as the Transnational Postcolonial Icon, Forum for Modern Language Studies, 45, 2, p. 203, 2009.

SKOTNES, Pippa (Ed.). Miscast: Negotiating the Presence of the Bushmen. Cape Town: University of Cape Town Press, 1996.

VIVEIROS DE CASTRO, Eduardo. Equívocos da identidade. In: GONDAR \& DOBEDEI (Org.). O que é memória social? Rio de Janeiro: Contracapa, 2006.

WESSELS, Michael (2012). The Khoisan Origins of the Interconnected World View in Antjie Krog's Begging to be Black. Current Writing: Text and Reception in Southern Africa, 24:2, 186-197, DOI: 10.1080/1013929X.2012.706928.

Recebido em 20 de novembro de 2020

Aceito em 15 de dezembro de 2020 